\title{
FORUM
}

\section{Tuberculosis prevention in HIV-infected pregnant women in South Africa}

\author{
C E Martin, V Black \\ WITS Reproductive Health and HIV Institute, Faculty of Health Sciences, University of the Witwatersrand, Johannesburg \\ C E Martin, MB ChB, Dip HIV Man, DTM\&H \\ V Black, BSc, MB ChB, Dip HIV Man, DTM\&H
}

Corresponding author: C E Martin (cmartin@wrhi.ac.za)

\begin{abstract}
The high burden of HIV and tuberculosis (TB) among pregnant women in South Africa contributes to a high maternal mortality rate. Isoniazid preventive therapy (IPT) is recommended for the prevention of active TB in HIV-infected individuals, including pregnant women. However, there are few data regarding IPT use in the latter, with concern regarding the concurrent use of IPT with nevirapine in pregnancy, as both treatments are hepatotoxic. The benefit and safety of IPT in HIV-infected pregnant women has not been established. We recommend a simplification of HIV and TB interventions by providing triple antiretroviral therapy to all HIV-infected pregnant women.
\end{abstract}

S Afr J HIV Med 2012;13(4):182-184. DOI:10.7196/SAJHIVMED.789

Maternal deaths in South Africa (SA) continue to rise, despite the target of the fifth Millennium Development Goal (MDG) of a $75 \%$ reduction in maternal mortality by 2015 . This target cannot be addressed without an appreciation of the effect of HIV and tuberculosis (TB) on maternal mortality in the country: the antenatal HIV sero-prevalence stands at $29.4 \%,{ }^{1}$ and $\mathrm{HIV}$ is the most common contributory condition to maternal mortality. ${ }^{2} \mathrm{~A}$ number of studies have confirmed the contribution of HIV in maternal mortality and morbidity. ${ }^{3-5}$

The prevalence of TB in HIV-infected pregnant women in SA is similar to that of the general population: approximately $795 / 100000{ }^{6}$ In 2009, the prevalence of active TB in HIVinfected women attending antenatal care in Soweto, Gauteng Province, was found to be $688 / 100$ 000; higher than the prevalence in HIV-uninfected women (201/100 000). ${ }^{7}$ These findings were comparable with data from Durban, KwaZuluNatal, where prevalence rates of active TB between 1996 and 1998 were 774/100 $000 \mathrm{HIV}$-infected pregnant women; 10 times higher than the prevalence for HIV-uninfected pregnant women. ${ }^{8}$

It is well established that TB and HIV are closely linked. An estimated $70 \%$ of adults presenting with new cases of TB in SA are co-infected with HIV, with TB being the most common cause of morbidity and mortality in HIV-infected individuals. ${ }^{9}$ TB is a leading cause of maternal mortality and morbidity, causing $15 \%$ of all maternal mortality in high HIV prevalence settings, and $15-34 \%$ of indirect obstetric maternal mortality. ${ }^{10}$ In SA between 2008 and 2010, TB accounted for 27\% of deaths in women who died of AIDS-related complications during pregnancy, childbirth or the puerperium. ${ }^{2}$ The findings of a study in Durban revealed a 3-fold higher maternal mortality ratio (MMR) among HIV-infected women with TB (12 170/100 000 live births) compared with TB-infected HIV- uninfected women (3 850/100 000 live births) in the absence of antiretroviral therapy (ART). ${ }^{11}$ Of the women diagnosed with TB, 79\% were co-infected with HIV. ${ }^{11}$ Similarly high MMRs in TB/HIV-co-infected women have been observed in a number of studies in sub-Saharan Africa. ${ }^{4,12-14}$

\section{The challenge of TB diagnosis in HIV-infected pregnant women}

Although diagnostic approaches to $\mathrm{TB}$ are similar for HIVinfected pregnant women as they are for HIV-uninfected and non-pregnant women, there are major challenges to the diagnosis of TB in the former. The symptoms of TB may be nonspecific in pregnancy, or even absent, mimicking physiological changes. Weight loss associated with TB disease may be masked by normal weight gain in pregnancy. ${ }^{15}$ The disease may only present post delivery in either the mother or infant. ${ }^{16}$ Furthermore, clinical signs of HIV may overlap with those of TB and there may be a wide differential diagnosis. ${ }^{16} \mathrm{HIV}$ infected adults may also have a high prevalence of subclinical TB disease, ${ }^{17}$ with $\mathrm{HIV}$-infected pregnant women also less likely to be sputum acid-fast bacilli smear-positive than HIVuninfected pregnant women with TB disease. ${ }^{7,18}$ Barriers to accessing care may contribute further to the under-diagnosis of TB in these women.?

\section{TB prevention strategies in the context of HIV}

TB prevention, diagnosis and treatment in HIV-infected pregnant women should be integrated into routine maternal healthcare services. Key strategies adopted by the World Health Organization (WHO) to decrease the effect of TB on people living with HIV include the 3 I's: intensified TB case finding, 
isoniazid preventative therapy (IPT); and infection control for TB. ${ }^{19}$

It has been established that the use of IPT reduces the risk of active TB in HIV-infected individuals. However, this is more pronounced in those with a positive tuberculin skin test (TST). ${ }^{20,21}$ The most recent meta-analysis of the treatment of latent TB infection (LTBI) in HIV-infected individuals encompassed 12 trials and 8578 HIV-infected participants. ${ }^{20}$ Overall, the treatment of LTBI reduced the risk of active TB by $32 \%$ (risk ratio (RR) 0.68 ; 95\% confidence interval (CI) $0.54-0.85$ ). This benefit was stronger in TST-positive individuals (RR 0.38 ; 95\% CI 0.25 - 0.57) than in TST-negative individuals (RR 0.89; 95\% CI 0.64 - 1.24). Isoniazid (INH) monotherapy was found to reduce mortality only in those who were TST-positive. However, overall, there was no evidence that preventive therapy reduced all-cause mortality. ${ }^{20} \mathrm{~A}$ randomised controlled trial (RCT) of 6- v. 36-month IPT for TB in HIV-infected adults in Botswana also found a benefit of IPT in TST-positive individuals, but no benefit for those who were TST-negative. ${ }^{21}$

The use of ART in HIV-infected adults also reduces the incidence of TB. In a metaanalysis of 9 observational cohort studies, a $67 \%$ reduction in $\mathrm{TB}$ incidence across a range of $\mathrm{CD} 4$ cell counts and $\mathrm{WHO}$ disease stages was reported..$^{22} \mathrm{~TB}$ risk reductions with ART occur irrespective of TST reactions..$^{22,23}$ Although the greatest absolute risk reduction of TB is observed in individuals with the most advanced immunodeficiency at baseline, ${ }^{22}$ patients starting ART earlier, at higher CD4 cell counts, have a 2 -fold lower risk of $\mathrm{TB}$ compared with those initiating ART at lower CD4 cell counts. ${ }^{23,24}$ HIV-infected individuals starting ART with low CD4 cell counts remain at high risk of TB until CD4 cell count recovery has occurred. ${ }^{23}$

Studies have suggested that there may be additional benefit to concurrent IPT and ART. $^{21,25,26}$ In a recent RCT in Khayelitsha, a $37 \%$ reduction in the risk of $\mathrm{TB}$ was evident in individuals receiving IPT and ART compared with patients receiving ART only (RR 0.63; $95 \%$ CI 0.41 - 0.94). However, the risk of stopping INH or placebo due to grade 3 or 4 elevation of alanine transaminase (ALT) was twice as high in the patients receiving IPT compared with those receiving placebo and, overall, there was no evidence of mortality benefit. ${ }^{27}$ The effect of timing of IPT v. ART initiation has not been determined. Experts recommend not initiating IPT at the same time as ART, but rather delaying initiation until stabilisation on ART, at approximately 3 months. ${ }^{22,28}$

\section{The safety of IPT in pregnant women}

Current national and international guidelines recommend the use of IPT for 6 months for all HIV-infected adults asymptomatic for $\mathrm{TB}$, including pregnant women. ${ }^{9,29}$ WHO advises that, although not a requirement for IPT initiation in HIV-infected individuals, TSTs may identify those who would benefit most from IPT. The American Thoracic Society (ATS) recommends a TST for the diagnosis of LTBI in pregnant women with a specific risk factor for LTBI or who are at risk for progression to TB disease. This includes women who are HIV-infected or who have a recent $\mathrm{TB}$ case contact. Although ATS acknowledge that treatment for LTBI in pregnancy is controversial, they do recommend such treatment for cases of recent TB or HIV infection where there is an increased risk of haematogenous spread of organisms to the placenta, as well as in situations with a high risk of progression of LTBI to disease. ${ }^{30}$ Guidelines do indicate that IPT can be administered during pregnancy, but it is unclear when and if IPT should be given if the pregnant woman is receiving ART.

There is little evidence available on IPT use in HIV-uninfected pregnant women in general. Furthermore, to our knowledge, there is no evidence available of the effectiveness of IPT in reducing TB risk in HIV-infected pregnant women.

In a study which modelled the costeffectiveness and outcomes of different treatment strategies for LTBI in pregnancy, antepartum IPT was anticipated to result in the fewest cases of TB and be more cost-effective than no treatment or delaying treatment until postpartum..$^{31}$ Ante- and postpartum IPT was predicted to be less costly and result in a higher life expectancy than no treatment, despite a higher mortality rate due to hepatitis in the antepartum group. ${ }^{31}$ However, HIV infection and the use of ART were not taken into account.

$\mathrm{INH}$ is not teratogenic, even if given during the first trimester, ${ }^{32}$ but it has a number of known adverse effects which include neurological toxicity, skin rash and hepatotoxicity. Reported rates of INHassociated clinical and biochemical hepatitis range from $0 \%$ to $5 \%{ }^{28}$ In a systematic review of the risk of age-related hepatotoxicity in LTBI treatment, a median hepatotoxicity rate of 1.8\% was reported. Studies with close monitoring of hepatotoxicity reported lower rates of hepatotoxicity than those without monitoring. In studies with available information, there was only one reported case of hospitalisation and no reported cases of mortality. ${ }^{33}$ A comparison of treatment with rifampicin for 4 months $\mathrm{v}$. INH for 9 months found rates of hepatotoxicity of $1.4-5.2 \%$ in the latter. ${ }^{34}$

Although it is not conclusive whether the side-effects of INH are worsened by pregnancy, 2 studies have suggested that pregnant or postpartum women may be at higher risk of hepatotoxicity. ${ }^{30}$ Pyridoxine supplementation is recommended in HIVinfected and pregnant individuals taking INH to prevent neurological toxicity. ${ }^{30}$

The rate of INH-associated hepatitis in HIV-infected individuals appears to be similar to that of the general population. ${ }^{35}$ In a Brazilian study of HIV-infected patients receiving IPT (with or without ART), 1.2\% of participants had adverse reactions leading to discontinuation of IPT. $^{36}$ In a study of $1762 \mathrm{HIV}$-infected individuals receiving IPT in Botswana, 1.1\% developed hepatitis, and one death was reported. ${ }^{28}$ In Khayelitsha, a hepatitis risk of $2.9 \%$ was reported in patients receiving IPT and ART. ${ }^{27}$

Some antiretroviral drugs are known to be associated with significant adverse effects, including hepatotoxicity. A $4.4 \%$ prevalence of grade $3-4$ hepatotoxicity and $7 \%$ prevalence of grade 1 - 2 hepatotoxicity have been associated with nevirapine (NVP) use in HIV-infected pregnant women. The rate of NVP side-effects is higher in women with CD4 counts $>250$ cells $/ \mathrm{mm}^{3} .^{37} \mathrm{NVP}$ is part of the first-line regimens used to treat HIVinfected pregnant women with CD4 counts $\leq 350$ cells $/ \mathrm{mm}^{3}$ or WHO clinical stage 3 or 4 conditions in SA.

Increased rates of INH-associated hepatitis have been reported in patients receiving NVPcontaining ART regimens compared with those receiving efavirenz (EFV)-containing regimens. In a previous study, the use of ART by 480 patients was not associated with INH-hepatitis, although those receiving NVP had a higher rate of hepatitis (2\%) than those receiving $\mathrm{EFV}$ (0.9\%). Interestingly, a CD4 cell count $<200$ cells $/ \mathrm{mm}^{3}$ was associated with INH hepatitis (RR 2.80; 95\% CI $1.13-6.84$ ). ${ }^{28}$

\section{Conclusion}

There is a high burden of HIV and TB among pregnant women in SA, contributing to a high 
MMR. Despite ART availability in the country, the recent maternal mortality survey showed that the majority of women who died from HIV did not access ART. If we are to progress towards the MDG targets, interventions need to be safe, easy to implement and simplified to maximise early nurse initiation of ART. IPT initiation after ART in pregnancy adds additional steps to antenatal care, which is currently under-resourced. This may further burden the programme and compromise other areas of care, for a benefit apparently limited to TST-positive individuals and that, to date, has no evidence of efficacy in pregnancy.

Screening all pregnant women for $\mathrm{TB}$ and HIV is imperative. Those with TB disease should be treated accordingly, with contact tracing and screening of household contacts. Although not currently stipulated in guidelines, all HIV-infected pregnant women should be considered for initiation onto combination ART. With this approach, IPT initiation may be better deferred until the postpartum period. Triple ART for all HIVinfected pregnant women will reduce motherto-child HIV transmission, adverse pregnancy outcomes, maternal mortality, horizontal transmission to uninfected partners and, specifically, the incidence of TB disease.

\section{References}

1. National Department of Health (DoH). The National Antenatal Sentinel HIV and Syphilis Prevalence Survey in South Africa. Pretoria: DoH, 2010. http:// www.health-e.org.za/documents/85d3dad6136e8ca9 d02cceb7f4a36145.pdf (accessed 2 November 2011).

2. National Committee on Confidential Enquiries into Maternal Deaths. Saving Mothers 2008 - 2010: Fifth Report on Confidential Enquiries into Maternal Deaths in South Africa. http://www.doh.gov.za/list. php?type=Maternal\%20and $\% 20$ child $\% 20$ health (accessed 30 May 2012).

3. Coutsoudis A, England K, Rollins N, Coovadia $\mathrm{H}$, Newell M-L, Bland R. Women's morbidity and mortality in the first 2 years after delivery according to HIV status. AIDS 2010;24(18):2859-2866. [http:// dx.doi.org/10.1097/QAD.0b013e32834041b7]

4. Zvandasara P, Hargrove JW, Ntozini R, et al. Mortality and morbidity among postpartum HIVpositive and HIV-negative women in Zimbabwe: Risk factors, causes, and impact of single-dose postpartum vitamin A supplementation. J Acquir Immune Defic Syndr 2006;43(1):107-116. [http:// dx.doi.org/10.1097/01.qai.0000229015.77569.c7]

5. Walson JL, Brown ER, Otieno PA, et al. Morbidity among HIV-1-infected mothers in Kenya: Prevalence and correlates of illness during 2-year postpartum follow-up. J Acquir Immune Defic Syndr 2007;46(2):208-215. [http://dx.doi.org/10.1097/ QAI.0b013e318141fcc0]

6. World Health Organization (WHO). Tuberculosis country profiles: South Africa. Geneva: WHO, 2012. http://www.who.int/tb/data (accessed 23 July 2012).

7. Gounder CR, Wada NI, Kensler C, et al. Active tuberculosis case-finding among pregnant women presenting to antenatal clinics in Soweto, South Africa.
I Acquir Immune Defic Syndr 2011;57:e77-e84 [http://dx.doi.org/10.1097/QAI.0b013e31821ac9c1]

8. Pillay T, Khan M, Moodley J, et al. The increasing burden of tuberculosis in pregnant women, newborns and infants under 6 months of age in Durban, KwaZulu-Natal. S Afr Med J 2001;91(11):983-987.

9. National Department of Health, South African National AIDS Council. Guidelines for Tuberculosis Preventative Therapy Among HIV Infected Individuals in South Africa 2010. http://www.rhru. co.za/Resources/Documents/2010\%20TB\%20 Prophylaxis\%20Guidelines.pdf (accessed 29 November 2011).

10. Getahun H, Sculier D, Sismanidis C, Grzemska M, Raviglione M. Prevention, diagnosis, and treatment of tuberculosis in children and mothers: Evidence for action for maternal, neonatal, and child health services. J Infect Dis 2012;205(2):S216-227. [http:// dx.doi.org/10.1093/infdis/jis009]

11. Khan M, Pillay T, Moodley JM, Connolly CA. Maternal mortality associated with tuberculosisHIV-1 co-infection in Durban, South Africa. AIDS 2001:15(14):1857-1863.

12. Black V, Brooke S, Chersich MF. Effect of human immunodeficiency virus treatment on maternal mortality at a tertiary center in South Africa: A 5-year audit. Obstet Gynecol 2009;114(2):292-299. [http://dx.doi.org/10.1097/AOG.0b013e3181af33e6]

13. Bradshaw D, Chopra M, Kerber K, et al. Every death counts: use of mortality audit data for decision making to save the lives of mothers, babies, and children in South Africa. Lancet 2008;371(9620):1294-1304 org/10.1016/S0140-6736(08)60564-4]

14. Pillay T, Khan M, Moodley J, Adhikari M, Coovadia H. Perinatal tuberculosis and HIV-1: Consideration for resource-limited settings. Lancet Infect Dis 2004;4(3):155-165. [http://dx.doi.org/10.1016/S14733099(04)00939-9]

15. Loto OM, Awowole I. Tuberculosis in pregnancy: A review. J Pregnancy 2012;379271. [http://dx.doi. org/10.1155/2012/379271]

16. Thillagavathie P. Current issues in maternal and perinatal tuberculosis: impact of the HIV-1 epidemic. Semin Neonatol 2000;5(3):189-196.

17. Oni $T$, Burke R, Tsekela R, et al. High prevalence of subclinical tuberculosis in HIV-1-infected persons without advanced immunodeficiency: implications for TB screening. Thorax 2011;66(8):669-673. [http://dx.doi.org/10.1136/thx.2011.160168]

18. Kali PBN, Gray GE, Violari A, Chaisson RE, McIntyre JA, Martinson NA. Combining PMTCT with active case finding for tuberculosis. J Acquir Immune Defic Syndr 2006;42(3):379-381. [http:// dx.doi.org/10.1097/01.qai.0000218434.20404.9c]

19. World Health Organization (WHO). WHO Three I's Meeting Intensified Case Finding (ICF), Isoniazid Preventive Therapy (IPT) and TB Infection Control (IC) for people living with HIV Report of a Joint World Health Organization HIV/AIDS and TB Department Meeting. Geneva: WHO, 2008. http:// www.who.int/hiv/pub/meetingreports/WHO_3Is_ meeting_report.pdf (accessed 2 November 2011).

20. Akolo C, Adetifa I, Shepperd S, VolminkJ. Treatment of latent tuberculosis infection in HIV infected persons. Cochrane Database Syst Rev 2010;(1):CD000171. [http://dx.doi.org/10.1002/14651858.CD000171. pub3]

21. Samandari T, Agizew TB, Nyirenda S, et al. Sixmonth versus 36-month isoniazid preventive treatment for tuberculosis in adults with HIV infection in Botswana: A randomised, double-blind, placebo-controlled trial. Lancet 2011;377(9777):1588-1598. [http://dx.doi. org/10.1016/S0140-6736(11)60204-3]

22. Lawn SD, Wood R, De Cock KM, Kranzer K, Lewi JJ, Churchyard GJ. Antiretrovirals and isoniazid preventive therapy in the prevention of HIV associated tuberculosis in settings with limited health care resources. Lancet Infect Dis 2010;10(7):489-498 [http://dx.doi.org/10.1016/S1473-3099(10)70078-5]

23. Lawn SD, Harries AD, Williams BG, et al. Antiretroviral therapy and the control of HIV associated tuberculosis. Will ART do it? Int Tuberc Lung Dis 2011;15(5):571-581. [http://dx.doi. org/10.5588/ijtld.10.0483]

24. Severe P, Juste MAJ, Ambroise A, et al. Early versus standard antiretroviral therapy for HIV-infected adults in Haiti. N Engl J Med 2010;363(3):257-265. [http://dx.doi.org/10.1056/NEJMoa0910370]

25. Golub JE, Saraceni V, Cavalcante SC, et al. The impact of antiretroviral therapy and isoniazid preventive therapy on tuberculosis incidence in HIV-infected patients in Rio de Janeiro, Brazil. AIDS 2007;21(11):1441-1448. [http://dx.doi.org/10.1097/ QAD.0b013e328216f441]

26. Golub JE, Pronyk P, Mohapi L, et al. Isoniazid preventive therapy, HAART and tuberculosis risk in HIV-infected adults in South Africa: A prospective cohort. AIDS 2009;23(5):631-636. [http://dx.doi. org/10.1097/QAD.0b013e328327964f]

27. Rangaka MX, Boulle A, Wilkinson RJ, et al. Randomized controlled trial of isoniazid preventive therapy in HIV-infected persons on antiretroviral therapy. Nineteenth International AIDS Conference, Washington DC, 22 - 27 July 2012;THLBB03.

28. Tedla Z, Nyirenda S, Peeler C, et al. Isoniazidassociated hepatitis and antiretroviral drugs during tuberculosis prophylaxis in HIV-infected adults in Botswana. Am J Respir Crit Care Med 2010;182(2):278-285. [http://dx.doi.org/10.1164/ rccm.200911-1783OC]

29. World Health Organization (WHO). Guidelines for intensified tuberculosis case-finding and isoniazid preventive therapy for people living with HIV in resource-constrained settings. Geneva: WHO, 2011. http://whqlibdoc.who. int/publications/2011/9789241500708_eng.pdf (accessed 21 November 2011).

30. American Thoracic Society, Centers for Disease Control and Prevention. Targeted tuberculin testing and treatment of latent tuberculosis infection. Am Respir Crit Care Med 2000;161(3):S221-S247.

31. Boggess KA, Myers ER, Hamilton CD. Antepartum or postpartum isoniazid treatment of latent tuberculosis infection. Obstet Gynecol 2000;96(5):757-762.

32. Bothamley G. Drug treatment for tuberculosis during pregnancy: Safety considerations. Drug Saf 2001;24(7):553-565

33. Kunst H, Khan KS. Age-related risk of hepatotoxicity in the treatment of latent tuberculosis infection: A systematic review. Int $\mathrm{J}$ Tuberc Lung Dis 2010;14(11):1374-1381.

34. Ziakas PD, Mylonakis E. 4 months of rifampin compared with 9 months of isoniazid for the management of latent tuberculosis infection: A meta-analysis and cost-effectiveness study that focuses on compliance and liver toxicity. Clin Infect Dis 2009;49(12):1883-1889. [http://dx.doi. org/10.1086/647944

35. Saukkonen JJ, Cohn DL, Jasmer RM, et al. An official ATS statement: Hepatotoxicity of antituberculosis therapy. Am J Respir Crit Care Med 2006;174(8):935-952. [http://dx.doi.org/10.1164/ rccm.200510-1666ST]

36. Durovni B, Cavalcante SC, Saraceni V, et al. The implementation of isoniazid preventive therapy in HIV clinics: The experience from the TB/HIV in Rio (THRio) Study. AIDS 2010;24(5):S49-S56. [[http:// dx.doi.org/10.1097/01.aids.0000391022.95412.a6]

37. McKoy JM, Bennett CL, Scheetz MH, et al Hepatotoxicity associated with long- versus short-course HIV-prophylactic nevirapine use: A systematic review and meta-analysis from the Research on Adverse Drug events And Reports (RADAR) project. Drug Saf 2009;32(2):147-158. 